\title{
Endonasal Arteriovenous Fistula Following Transsphenoidal Resection of Pituitary Adenoma Treated with N-Butyl-2-Cyanoacrylate
}

\author{
${ }^{1}$ Department of Neurosurgery, Endovascular Neurosurgery Service, \\ Hospital Nacional Guillermo Almenara Irigoyen-EsSalud, La \\ Victoria, Lima, Peru
}

Giancarlo Saal-Zapata ${ }^{1}$ Walter Durand Castro ${ }^{1}$ Rodolfo Rodriguez Varela ${ }^{1}$

\begin{abstract}
Address for correspondence Saal-Zapata Giancarlo, MD, Grau Avenue 800, La Victoria, Lima 13, Perú (e-mail: gian_carlo1987@hotmail.com; gsaal1987@gmail.com).
\end{abstract}

\begin{abstract}
Keywords

- pituitary

- arteriovenous fistula

- N-butyl-2-

cyanoacrylate

- transsphenoidal

surgery

Vascular lesions of the external carotid artery after transsphenoidal pituitary surgery are rare. Immediate diagnosis must be done and endovascular embolization is the treatment of choice.

We report the case of a 53-year-old woman with visual complaints who underwent transsphenoidal surgery of a pituitary adenoma with good clinical and radiological evolution. Five days after surgery nasal tampons were removed and suddenly the patient started to bleed: nasal packing and air way protection were required. Digital subtraction angiography revealed an endonasal arteriovenous fistula with a feeder from the sphenopalatine artery and drainage to sphenopalatine veins. Embolization with N-butyl-2-cyanoacrylate was performed with total obliteration of the arteriovenous fistula. We suggest that endovascular treatment of external carotid artery lesions after transsphenoidal surgery is the best alternative in cases of active bleeding.
\end{abstract}

\section{Introduction}

Vascular injuries following transsphenoidal surgery of pituitary tumors are rare and challenging complications representing around $1 \%$ of the cases..$^{1-5}$ They more frequently involve the internal carotid artery (ICA) and less commonly the external carotid artery (ECA). ${ }^{6}$

The involvement of the ICA can be evident during surgery with profuse and uncontrollable bleeding. When this occurs, nasal packing and sometimes definitive carotid occlusion must be done. ${ }^{1,7}$ On the other hand, ECA injuries are even more rare; and few cases of pseudoaneurysms and arteriovenous fistulas (AVF) have been reported in the literature after transsphenoidal surgery. ${ }^{7-11}$

Vascular lesions in this two arteries can be life-threatening, requiring air way protection and immediate digital subtraction angiography (DSA) for diagnosis with the possibility of definitive treatment. ${ }^{12}$

We present the case of a patient who underwent trans-sphenoidal surgery of a pituitary tumor and developed profuse nasal bleeding in a delayed fashion due to the presence of an iatrogenic endonasal arteriovenous fistula of the sphenopalatine artery. Successful treatment with embolization using N-butyl-2-cyanoacrylate was performed with complete obliteration of the AVF and absence of bleeding.

\section{Case Description}

A previously healthy 53 -year-old woman with 3 years of visual impairment was referred to our hospital. A brain magnetic resonance imaging showed a pituitary adenoma with suprasellar growth and optic chiasm involvement. Analytics revealed a normofunctional tumor.

Under general anesthesia, transsphenoidal resection was decided and performed through the right nostril: sphenoidal osteotomy with resection of sphenoidal mucosa and then osteotomy of sella turcica floor were performed. Tumor was resected without complications and there was no evidence of profuse bleeding, and no cerebrospinal fluid (CSF) leakage was observed during surgery. Hemostasis was performed with bipolar coagulation, fat, Surgicel (Johnson \& Johnson;, New Jersey, United States), and collagen. received

June 7, 2019

accepted

July 8, 2019

published online

September 30, 2019
Dol https://doi.org/

10.1055/s-0039-1698000 ISSN 2277-954X.
C2019 Neurological Surgeons'

Society of India
License terms

$($ (1) $\Theta \circledast$ 
Five days after the surgery, nasal tampons were removed and profuse nasal bleeding started, requiring air way protection and intensive care unit (ICU) support. Nasal packing was applied and DSA revealed an endonasal arteriovenous fistula with feeding branches from the sphenopalatine artery and drainage to sphenopalatine veins (-Fig. 1). Endovascular treatment was decided and patient accepted the procedure.

Under conscious sedation anesthesia, we approached the right femoral artery. A Chaperon 6 French guide catheter (Microvention; Tustin, California), BALT Magic $1.5 \mathrm{~F}$ microcatheter (Balt Extrusion; Montmorency, France), and Transend 0.014 (Stryker; Freemont, California, United States) microwire were navigated into the internal maxillary artery and sphenopalatine artery.

Selective angiography was performed confirming the presence of an $\operatorname{AVF}$ ( - Fig. 2).

We decided to perform the embolization using $0.3 \mathrm{~mL}$ of N-butyl-2 cyanoacrylate mixed with lipiodol. The control DSA showed complete obliteration of the vascular lesion and nasal tampons were removed without complications after the procedure. The patient was discharged 3 days after the embolization without active bleeding.

\section{Discussion}

Currently, sellar tumors are treated with different approaches: transsphenoidal microsurgery, open surgery, and endoscopic surgery. ${ }^{1,4}$ The election will depend on the surgeon's experience and the adequate equipment available.

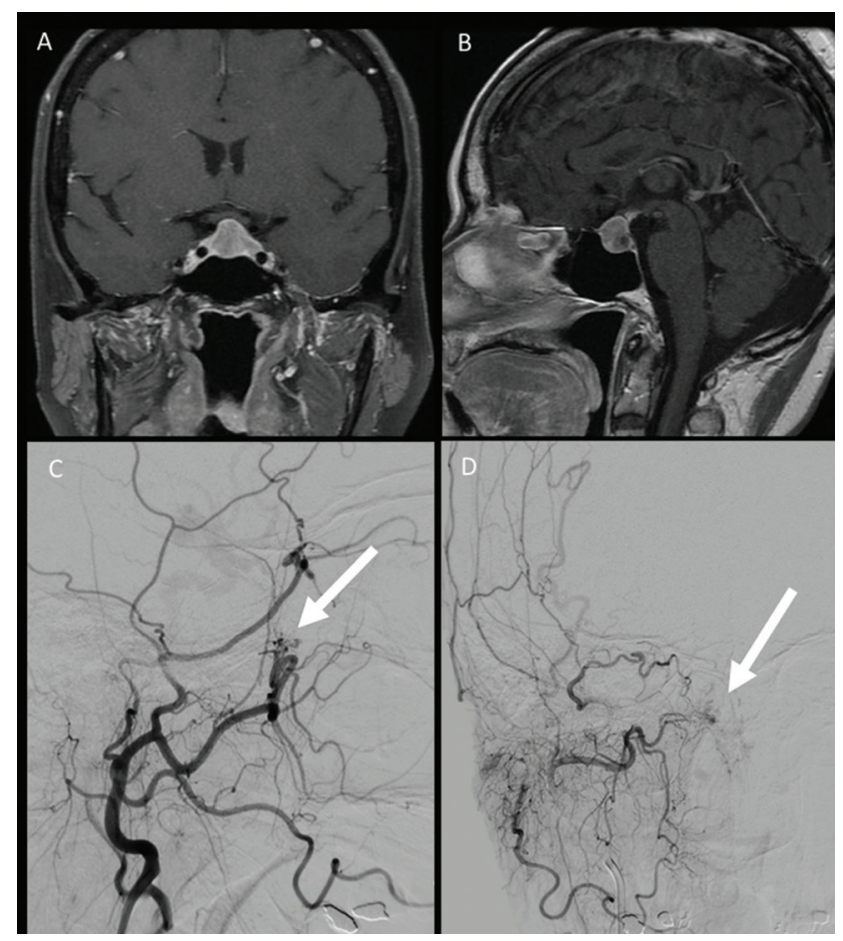

Fig. 1 Pituitary tumor with suprasellar growth and involvement of optic chiasm.(A) Frontal view and (B) lateral view. Digital subtraction angiography of the external carotid artery. (C) Lateral view reveals an arteriovenous fistula of the sphenopalatine artery. (D) Frontal view shows the arteriovenous fistula with its venous drainage.

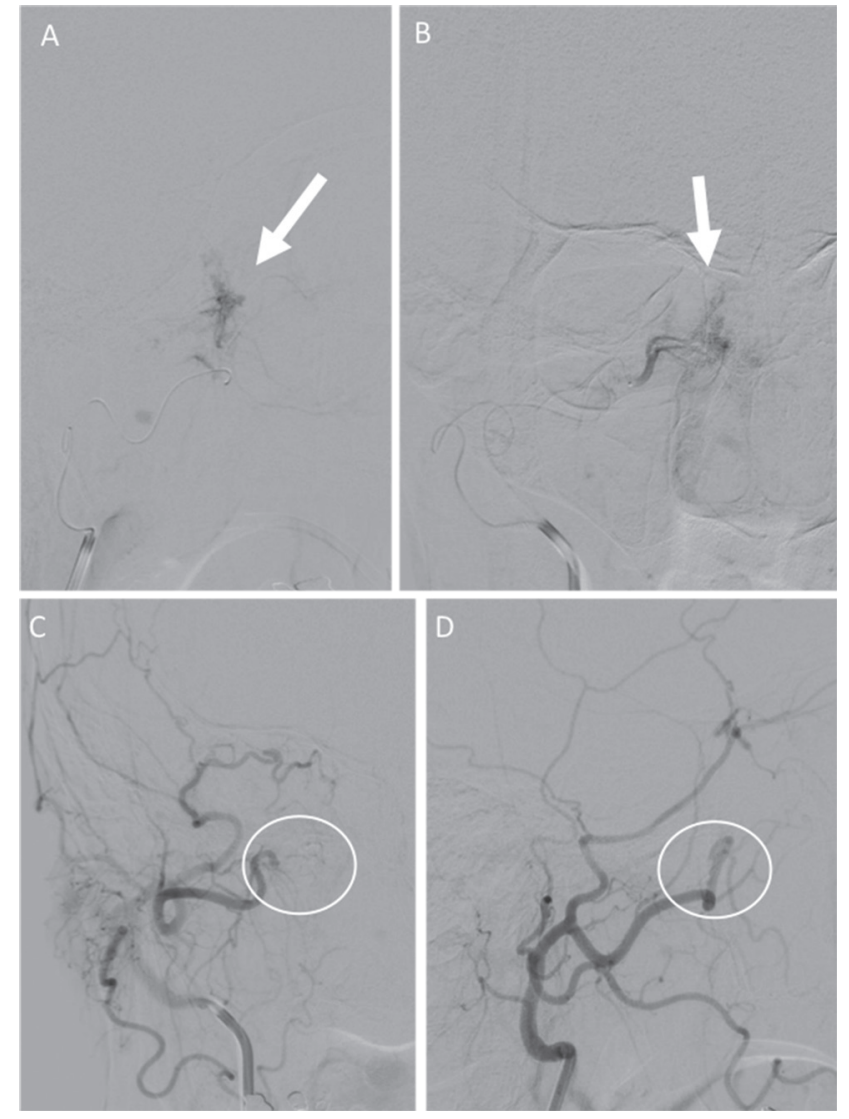

Fig. 2 Selective digital subtraction angiography of the internal maxillary artery.(A) Frontal and (B) lateral views confirming the presence of an arteriovenous fistula of the sphenopalatine artery. Post embolization digital subtraction angiography of external carotid artery. (C) Frontal and (D) lateral views showing the absence of the arteriovenous fistula.

At our institution, we use the trans-septal transsphenoidal approach for the treatment of pituitary tumors. This implies the dissection of nasal septum mucosa reaching the junction of the vomer with the sphenoid bone. ${ }^{9}$ Sometimes, this maneuver produces bleeding which is controlled with bipolar coagulation and in other occasions it is controlled with compression of the speculum. ${ }^{7}$ We routinely remove nasal tampons between the third and fifth postoperative days after surgery without complications; this allows an adequate healing process of the mucosa.

There are risk factors for vascular injuries due to trans-sphenoidal resections: invasive adenomas, second surgery, cavernous sinus involvement, radiotherapy, and previous use of drugs such as dopamine antagonists. ${ }^{3}$

ICA injuries include stenosis, pseudoaneurysms, and carotid cavernous fistulae and their treatment entails high morbidity and mortality. ${ }^{3}$ The treatment in this cases is endovascular and requires in some cases trapping of the artery. ${ }^{3,6,13}$

The sphenopalatine artery is found at the inferolateral margin of the sphenoid sinus and divides into two branches: a medial or septal branch which is the most frequently injured during dissection and the lateral branch that irrigates superior, medium, and inferior conchae.,3 When dissecting and trying to enlarge the entrance to the sphenoid sinus this 
artery can be injured. ${ }^{7}$ Sphenopalatine artery injuries include pseudoaneurysms and AVFs that are rare, such as in this case. ${ }^{3}$

When vascular injuries occur in these two arteries, endovascular treatment is mandatory: particles, coils, and embolic agents (N-butyl-cyanoacrylate, onyx) can be employed. ${ }^{12}$ In this case, we could be able to identify the injury and treat it achieving complete obliteration.

Eneling et al reported a similar case: the patient developed massive epistaxis 5 days after trans-sphenoidal surgery of a pituitary adenoma, the cause was an iatrogenic AVF. ${ }^{8}$ They used glue to obliterate the lesion and the patient's evolution was uneventful.

External carotid artery injuries are rare and few reports exist in the literature regarding their treatment. ${ }^{1,7-11}$ The most common type of injuries are the pseudoaneurysms, followed by AVFs.

Of the few reported cases, when an angiography was performed, it was difficult to identify injuries in both the internal and external carotid arteries. ${ }^{9}$ This was due to the nasal packing with compression of the lesion at the time of the procedure. In our case, despite nasal packing, we were able to identify the cause of the bleeding. Endovascular treatment was performed in all cases.

\section{Conclusion}

External carotid artery injuries following transsphenoidal surgery are very rare and can be life threatening due to profuse bleeding. Endovascular treatment is the treatment of choice, achieving complete obliteration using embolic agents without complications.

\section{Conflict of Interest}

None declared.

\section{References}

1 Black PM, Zervas NT, Candia GL. Incidence and management of complications of transsphenoidal operation for pituitary adenomas. Neurosurgery 1987;20(6):920-924
2 Berker M, Aghayev K, Saatci I, Palaoğlu S, Önerci M. Overview of vascular complications of pituitary surgery with special emphasis on unexpected abnormality. Pituitary 2010;13(2):160-167

3 Raymond J, Hardy J, Czepko R, Roy D. Arterial injuries in transsphenoidal surgery for pituitary adenoma; the role of angiography and endovascular treatment. Am J Neuroradiol 1997;18(4):655-665

4 Ciric I, Ragin A, Baumgartner C, Pierce D. Complications of transsphenoidal surgery: results of a national survey, review of the literature, and personal experience. Neurosurgery 1997;40(2):225-236, discussion 236-237

5 Agam MS, Zada G. Complications associated with transsphenoidal pituitary surgery: review of the Literature. Neurosurgery 2018;65(CN suppl 1):69-73

6 Çinar C, Bozkaya H, Parildar M, Oran I. Endovascular management of vascular injury during transsphenoidal surgery. Interv Neuroradiol 2013;19(1):102-109

7 Cockroft KM, Carew JF, Trost D, Fraser RA. Delayed epistaxis resulting from external carotid artery injury requiring embolization: a rare complication of transsphenoidal surgery: case report. Neurosurgery 2000;47(1):236-239

8 Eneling J, Karlsson PM, Rossitti S. Sphenopalatine arteriovenous fistula complicating transsphenoidal pituitary surgery: a rare cause of delayed epistaxis treatable by endovascular embolization. Surg Neurol Int 2016;7(Suppl 41):S1053-S1056

9 Nishioka H, Ohno S, Ikeda Y, Ohashi T, Haraoka J. Delayed massive epistaxis following endonasal transsphenoidal surgery. Acta Neurochir (Wien) 2007;149(5):523-526, discussion 526-527

10 Halbach VV, Higashida RT, Hieshima GB, Hardin CW. Arteriovenous fistula of the internal maxillary artery: treatment with transarterial embolization. Radiology 1988;168(2):443-445

11 Campbell RG. Sphenopalatine artery pseudoaneurysm after endoscopic sinus surgery: a case report and literature review. Ear Nose Throat J 2012;91(2):E4-E11

12 Dubel GJ, Ahn SH, Soares GM. Transcatheter embolization in the management of epistaxis. Semin Intervent Radiol 2013;30(3):249-262

13 Sylvester PT, Moran CJ, Derdeyn CP, et al. Endovascular management of internal carotid artery injuries secondary to endonasal surgery: case series and review of the literature. J Neurosurg 2016;125(5):1256-1276 